\title{
PROMOÇÃO DE ENRAIZAMENTO DE MICROTOLETES DE CANA-DE-AÇÚCAR PELO USO CONJUNTO DE SUBSTÂNCIAS HÚMICAS E BACTÉRIAS DIAZOTRÓFICAS ENDOFÍTICAS ${ }^{(1)}$
}

\author{
Roberto Batista Marques Júnior ${ }^{(2)}$, Luciano Pasqualoto Canellas ${ }^{(3)}$, \\ Lúcia Gracinda da Silva ${ }^{(4)} \&$ Fábio Lopes Olivares ${ }^{(5)}$
}

\begin{abstract}
RESUMO
Além do fornecimento direto de nutrientes por meio da mineralização da matéria orgânica ou pela fixação biológica de $\mathrm{N}_{2}$, as substâncias húmicas e as bactérias diazotróficas endofíticas podem afetar diretamente o metabolismo vegetal, modificando o padrão de crescimento e desenvolvimento das plantas. $O$ objetivo deste trabalho foi avaliar o efeito do uso em conjunto de ácidos húmicos (AH) e Herbaspirilum seropedicae, uma bactéria endofítica fixadora de $\mathrm{N}_{2}$, sobre o crescimento radicular de microtoletes de cana-de-açúcar do cultivar RB 72454 tratados termicamente ou não. Após o tratamento térmico, os microtoletes foram imersos por $12 \mathrm{~h}$ em água (controle), numa solução que continha $20 \mathrm{mg} \mathrm{L}^{-1} \mathrm{de} \mathrm{C}$ de AH isolados de vermicomposto, $H$. seropedicae estirpe HRC 54 na concentração de $10^{8} \mathrm{~mL}^{-1}$ células e o uso em conjunto de $\mathrm{AH}+H$. seropedicae. Foi observada a promoção significativa do crescimento radicular, com incrementos que variaram de 60 a $118 \%$ no comprimento e de 33 até $233 \%$ na área radicular dos tratamentos em relação às plantas-controle, com efeitos mais pronunciados em plantas tratadas termicamente. Na mesma direção, o efeito positivo da inoculação bacteriana e dos ácidos húmicos sobre a biomassa da parte aérea e das raízes foi significativo em relação ao controle apenas em toletes tratados termicamente. Para toletes não tratados, a inoculação não produziu efeitos significativos, apenas no caso da aplicação isolada de ácidos húmicos. O uso em conjunto ou isolado de AH e bactérias diazotróficas endofíticas não alterou significativamente o tamanho populacional das bactérias no tecido radicular em toletes que não receberam termoterapia. No
\end{abstract}

\footnotetext{
(1) Extraído da Tese de Mestrado do primeiro autor apresentada ao Programa de Pós-Graduação em Produção Vegetal da Universidade Estadual do Norte Fluminense - Darcy Ribeiro - UENF. Recebido para publicação em março de 2007 e aprovado em dezembro de 2007.

(2) Doutorando em Produção Vegetal, Universidade Estadual do Norte Fluminense - UENF. Laboratório de Solos, Av. Alberto Lamego 2000, CEP 28013-602 Campos dos Goytacazes (RJ). E-mail: robertobmjr@yahoo.com.br

(3) Professor Associado, UENF. Laboratório de Solos. E-mail: canellas@uenf.br

(4) Doutora em Biociências e Biotecnologia, Laboratório de Biologia Celular e Tecidual, UENF. E-mail: silvalug@yahoo.com

(5) Professor Associado, Laboratório de Biologia Celular e Tecidual, UENF. E-mail: fabioliv@uenf.br
} 
caso de toletes tratados termicamente, a inoculação, combinada ou não com ácidos húmicos, alterou o tamanho da população das bactérias nas raízes. A análise conjunta dos dados evidencia a importância da termoterapia na expressão dos efeitos benéficos da inoculação de estirpes selecionadas de $\boldsymbol{H}$. seropedicae, já para ácidos húmicos, as respostas positivas independem da termoterapia. A promoção do crescimento radicular por $\mathrm{AH}$ e a fixação biológica de $\mathrm{N}_{2}$ podem representar uma estratégia inovadora para produção sustentada em sistemas agrícolas.

Termos para indexação: Herbaspirillum seropedicae, termoterapia, ácidos húmicos.

\title{
SUMMARY: ROOTING OF MICRO SEED PIECES BY COMBINED USE OF HUMIC SUBSTANCES AND ENDOPHYTIC DIAZOTROPHIC BACTERIA IN SUGAR CANE
}

\begin{abstract}
Besides the direct nutritional effect of mineralization of organic matter or by biological nitrogen fixation activity, the humic substances and endophytic diazotrophic bacteria can directly influence plant metabolism, modifying plant growth and development patterns. The purpose of this study was to evaluate the effect of the combined use of humic acid (HA) and Herbaspirillum seropedicae, an endophytic nitrogen-fixing bacteria, on the root growth of seed pieces - heat-treated or not - of the sugarcane variety $R B 72454$. After hot water treatment, the cane cuttings were immersed for 12 hours as follows: in water (control plant), in $H A$ solution ( $20 \mathrm{mg} \mathrm{L}^{-1}$ of $C$ ) from vermicompost, in bacterial inoculant of $\mathrm{H}$. seropedicae, strain HRC54 $\left(10^{8}\right.$ cells $\left.\mathrm{mL}^{-1}\right)$, and in a combination of bacteria and HA. Root growth was improved by 60 to $118 \%$ in length and from $33 \%$ to $233 \%$ in surface area on sugarcane plant treatments compared to control, with more pronounced effect in plants under heat treatment. Likewise, the positive effect of the combinded treatment (bacteria inoculation and humic acid) on shoot and root biomass was significant compared to the control with heat-treated cuts. For non-heated seed pieces, bacteria inoculation did not result in a positive plant growth effect, but only in the presence of humic acid. The combined or isolated use of both HA and bacteria did not significantly modify the bacteria population in the root tissue of heat-untreated sugarcane. For heat-treated cuts, bacteria inoculation, combined or not with HA, increased the size of diazotrophic bacteria population on roots. The results highlight the importance of thermotherapy to increase the positive effect of the selected bacteria strain of $\mathrm{H}$. seropedicae. In the case of $\mathrm{HA}$ application, plant growth stimulation was not related to thermotherapy. The plant root growth promoting effect induced by both HA and the inoculation of selected nitrogen-fixing bacteria strain could represent an innovative approach to a sustainable sugarcane crop production.
\end{abstract}

Index terms: Herbaspirillum seropedicae, heat treatment, humic acid.

\section{INTRODUÇÃO}

As substâncias húmicas (SH) são o principal componente da matéria orgânica do solo e influenciam suas propriedades químicas, físicas e biológicas. O crescimento e o metabolismo das plantas são alterados com a aplicação de ácidos fúlvicos (Vaughan \& Malcolm, 1985; Varanini et al., 1993) e húmicos (Chen \& Aviad, 1990; Nardi et al., 2002) em solução. A avaliação do potencial de ácidos húmicos $(\mathrm{AH})$ isolados de diferentes fontes de matéria orgânica sobre o crescimento e desenvolvimento de plantas de interesse agronômico tem sido explorada em experimentos realizados em casa de vegetação (Façanha et al., 2002;
Chen et al.,2004; Canellas \& Façanha, 2004). Tais efeitos são refletidos na aceleração das taxas de crescimento radicular, incremento de biomassa vegetal e alterações na arquitetura do sistema radicular (e.g., incremento da emissão de pêlos radiculares e de raízes laterais finas), resultando em aumento da área superficial e, ou, no comprimento do sistema radicular. Embora as bases celulares e moleculares da ação de $\mathrm{AH}$ não estejam totalmente esclarecidas, estudos apontam para uma estimulação da atividade e promoção da síntese das enzimas $\mathrm{H}^{+}$-ATPases da membrana plasmática, num efeito tipicamente auxínico (Pinton et al., 1999; Canellas et al., 2002; Quaggiotti et al., 2004). 
$\mathrm{Na}$ última década, estudos com bactérias diazotróficas endofíticas têm-se intensificado graças às suas potencialidades como agente de promoção de crescimento e proteção de plantas. No Brasil, dentre outros, merecem destaque os estudos que envolvem interações endofíticas entre plantas da família Poaceae [p.ex. cana-de-açúcar (Saccharum hyb.); arroz (Oriza sativa); milho (Zea mays); sorgo (Sorghum bicolor); capim-elefante (Pennisetum purpureum)] e bactérias fixadoras de $\mathrm{N}_{2}$ do gênero Gluconacetobacter, Herbaspirillum, Azospirillum e Burkholderia (Döbereiner et al., 1992a,b).

Na cultura da cana-de-açúcar, os estudos relacionados com seleção de genótipos da planta e de estirpes bacterianas eficientes na fixação biológica de $\mathrm{N}_{2}(\mathrm{FBN})$ têm apontado para contribuições entre 30 a $70 \%$ do N obtido via FBN (Urquiaga et al., 1992; Oliveira et al., 2002). Em plantas micropropagadas de cana-deaçúcar, Olivares et al. (2000) evidenciaram o potencial de promoção do crescimento pela inoculação de estirpes selecionadas de $G$. diazotrophicus e $H$. seropedicae, com incrementos na biomassa radicular entre 50 e 350 \% em relação ao controle não inoculado. De modo similar aos ácidos húmicos, foram observadas alterações na geometria da raiz, incremento da proporção relativa de raízes finas, área e comprimento radiculares, bem como incremento no teor de $\mathrm{N}, \mathrm{P}$ e K em raízes e na parte aérea, causadas pela aplicação de bactérias.

A maior parte da cultura da cana na região Norte Fluminense é cultivada em Latossolos Amarelos, que são solos intemperizados, conhecidos como solos de tabuleiros (originados a partir do sedimento Barreiras), com baixo teor de matéria orgânica, naturalmente coesos e distróficos (Embrapa, 1999). A produtividade média da cultura é baixa, em torno de $45 \mathrm{Mg} \mathrm{ha}^{-1}$, e é limitada pela baixa pluviosidade média (menor que $1.000 \mathrm{~mm} \mathrm{ano}^{-1}$ ) e pela incidência de uma série de pragas e doenças (Chagas \& Matsuoka, 1988). O raquitismo, doença endêmica na região causada por Leifsonia xyli subsp. Xyli e observada pela primeira vez na região por Frederico Veiga em 1956, ainda é o principal causador de queda de produtividade nas áreas com histórico da doença (Carneiro Jr. et al., 2004). A desinfestação do material propagativo é feita pelo tratamento térmico dos toletes, i.e., imersão em água quente $\left(50,5{ }^{\circ} \mathrm{C}\right)$ por duas horas. O tratamento térmico visa a eliminar microrganismos fitopatogênicos, porém, reduz substancialmente a microbiota benéfica associada aos toletes (Reis et al.,1994) e diminui a taxa de germinação (Kimati et al., 2005). Supostamente, este tratamento pode facilitar a introdução de microrganismos benéficos por inoculação de toletes póstermoterapia e estimulação do enraizamento provocada pelas substâncias húmicas. A estimulação do crescimento das plantas pelo uso em conjunto de susbtâncias húmicas e bactérias diazotróficas endofíticas é uma estratégia que merece atenção, considerando seu potencial de incrementar a produção de forma sustentada.
O objetivo deste trabalho foi avaliar o efeito do uso combinado de ácidos húmicos e bactérias diazotróficas endofíticas sobre a promoção de desenvolvimento de microtoletes de cana-de-açúcar (RB 72-454) tratados termicamente.

\section{MATERIAL E MÉTODOS}

\section{Obtenção dos ácidos húmicos (AH)}

Os ácidos húmicos foram isolados de vermicomposto produzido a partir de esterco de curral e minhocas californianas vermelhas (Eisenia foetida). $\mathrm{O}$ procedimento de extração e purificação dos $\mathrm{AH}$ foi realizado de acordo com as recomendações da International Humic Substances Society (www.ihss.gated.edu) com pequenas modificações e, resumidamente, consistiu no uso de $\mathrm{NaOH} 0,5 \mathrm{~mol} \mathrm{~L}^{-1}$, na razão resíduo orgânico:solvente de 1:10 (v:v) em atmosfera inerte de $\mathrm{N}_{2}$ por quatro horas. Após esse período, a suspensão foi centrifugada por 20 min a $5.000 \mathrm{~g}$ e o sobrenadante recolhido e acidificado até $\mathrm{pH}$ 1,0-1,5 com $\mathrm{HCl} 6 \mathrm{~mol} \mathrm{~L}^{-1}$. A redissolução e precipitação foi repetida três vezes. Em seguida, adicionaram-se $200 \mathrm{~mL}$ de solução aquosa diluída de $\mathrm{HF}$ e $\mathrm{HCl}$ (preparada com $5 \mathrm{~mL}$ de $\mathrm{HCl}$ concentrado e $5 \mathrm{~mL}$ de HF concentrado e volume de solução completado para $1 \mathrm{~L}$ com água deionizada) e agitouse a amostra por oito horas. Após centrifugação, os $\mathrm{AH}$ foram lavados com água até teste negativo com $\mathrm{AgNO}_{3}$ e acondicionados em membranas de diálise com tamanho de exclusão de 14.000 Da. A diálise foi realizada com água destilada e monitorada por meio da medida da condutividade elétrica da solução. Após a diálise, os AH foram secos por liofilização. Foi determinada a composição elementar dos ácidos húmicos, obtendo-se teores de $\mathrm{C}, \mathrm{H}$ e $\mathrm{N}$ por meio de analisador automático (Perkin-Elmer) e, posteriormente, determinado o teor de cinzas por incineração da amostra em mufla a $750{ }^{\circ} \mathrm{C}$ durante oito horas. Os AH apresentaram 48,5 \% de C, 5,5\% de $\mathrm{H}$ e $3,2 \%$ de N. O teor de cinzas foi de $0,5 \% \pm$ $0,001 \%$. A composição das cinzas foi analisada, em duplicata, por absorção atômica em forno de plasma após digestão sulfúrica, seguida da perclórica, de uma massa conhecida de cinzas dos AH. Foi detectada nas cinzas a presença de $\mathrm{Si}\left(13,07 \pm 2,26 \mathrm{~g} \mathrm{~kg}^{-1} \mathrm{de}\right.$ cinzas), Fe (9,78 $\pm 0,34 \mathrm{~g} \mathrm{~kg}^{-1}$ de cinzas $), \mathrm{Al}$ $\left(0,319 \pm 0,092 \mathrm{~g} \mathrm{~kg}^{-1}\right.$ de cinzas$), Z n\left(0,042 \pm 0,004 \mathrm{~g} \mathrm{~kg}^{-1}\right.$ de cinzas) e $\mathrm{Cu}\left(0,012 \pm 0,002 \mathrm{~g} \mathrm{~kg}^{-1}\right.$ de cinzas $)$.

\section{Obtenção do inóculo bacteriano}

A escolha do inóculo bacteriano foi baseada em trabalhos anteriores que indicaram resposta positiva no desenvolvimento de toletes de cana-de-açúcar (Olivares, 2001; Olivares, 2002; Oliveira et al., 2002; Canuto et al., 2003). O inóculo de Herbaspirillum seropedicae estirpe HRC 54 (depositada na coleção de 
cultura da Embrapa Agrobiologia com designação BR 11335) e originalmente isolada de raízes desinfestadas da cana-de-açúcar var SP 70-1143, foi obtido a partir de crescimento bacteriano em meio DYG'S líquido (Rodrigues Neto, 1986), à temperatura de $30^{\circ} \mathrm{C}$, por $36 \mathrm{~h}$, sob $140 \mathrm{rpm}$.

\section{Tratamento térmico para obtenção de plantas sadias}

O material propagativo selecionado (estacas toletes com uma gema) com 10-12 cm de comprimento foi submetido ao tratamento térmico, usado normalmente na região para inativação de células de Leifsonia xyli subsp. xyli. Utilizou-se um equipamento pequeno tipo banho-maria, com capacidade para $21 \mathrm{~L}$ de água, com circulação e controle de temperatura. Inicialmente, os toletes foram acondicionados em saquinhos de nylon (tipo saco de batata), os quais foram, então, tratados com água quente a $50,5^{\circ} \mathrm{C}$ por duas horas no banhomaria.

\section{Aplicação dos tratamentos e instalação do experimento}

Os microtoletes, previamente tratados termicamente ou não, foram imersos durante $12 \mathrm{~h}$ em meio de cultura (DYG'S líquido) na presença dos seguintes tratamentos: controle (água), ácidos húmicos (AH) isolados de vermicomposto na concentração de $20 \mathrm{mg}$ de $\mathrm{C}$ na forma de ácidos húmicos por litro de solução (20 $\mathrm{mg} \mathrm{L}^{-1} \mathrm{de}_{\mathrm{AH}}$ ); Herbaspirillum seropedicae estirpe HRC 54 na concentração final de $10^{8} \mathrm{~mL}^{-1}$ de células no meio (Bac) e o uso conjunto de $\mathrm{AH}$ e bactérias diazotróficas endofíticas (Bactéria + $\mathrm{AH}$ ), nas referidas concentrações. Após esse período, os toletes foram transferidos para vasos Leonard e mantidos em casa de vegetação na Universidade Estadual do Norte Fluminense, durante o período experimental de 45 dias. $\mathrm{O}$ delineamento experimental foi inteiramente casualisado com seis repetições.

\section{Características de crescimento vegetal analisa- das e análise estatística}

As características avaliadas foram: contagem da população bacteriana inoculada na raiz, como descrito por Döbereiner et al. (1995), matéria seca de raiz e parte aérea, área e comprimento radiculares. As massas foram obtidas utilizando uma balança analítica, e a área e comprimento radicular estimados com o auxílio de um scanner para obtenção da imagem digital e com o auxílio do software analisador digital de imagens Delta-T scan ${ }^{\circledR}$. A contagem de bactérias presentes no tecido radicular foi realizada por meio da técnica do Número Mais Provável (NMP). O número de bactérias na raiz (expresso em $\log \mathrm{n}^{0} \mathrm{de}$ bactérias por g de massa fresca da raiz) foi estimado, tomando-se amostras de $1 \mathrm{~g}$ das raízes por repetição para todos os tratamentos, diluídas seriadamente em solução salina $(\mathrm{NaCl} 0,85 \%)$ de $10^{-2}$ até $10^{-7} \mathrm{e}$ aplicando-se $100 \mu \mathrm{L}$ das diluições em frascos de vidro ( $\mathrm{v}=16 \mathrm{~mL}$ ), com $5 \mathrm{~mL}$ de meio JNFb semi-sólido sem adição de N (Baldani et al., 1992). Os frascos foram incubados a $30^{\circ} \mathrm{C}$, por sete dias; decorrido este período, avaliou-se o crescimento pela presença de uma película branca na superfície do meio. O número de bactérias foi obtido pela consulta à Tabela de McCrady (Döbereiner et al., 1995) para três repetições por diluição; tendo os valores sofrido transformação logarítmica. A análise estatística foi efetuada pelo software SAEG for Windows, desenvolvido pela Universidade Federal de Viçosa (UFV).

\section{RESULTADOS E DISCUSSÃO}

Verificou-se estímulo significativo no crescimento da parte aérea pelo controle nos toletes tratados termicamente com uso de $\mathrm{AH}, H$. seropedicae estirpe HRC 54 e pelo uso em conjunto de $\mathrm{AH}$ com as bactérias diazotróficas endofíticas (Figura 1). Nos toletes que não sofreram tratamento térmico, o estímulo do crescimento da parte aérea foi observado somente no tratamento com AH. Os toletes não tratados apresentaram, naturalmente, uma microbiota nativa. A elevada densidade de inóculo de bactérias endofíticas aplicada, além dos microrganismos nativos, leva a uma competição por carboidratos e outras biomacromoléculas. Este fato pode representar um dreno adicional consumindo a reserva dos microtoletes. Assim, o decréscimo no acúmulo de matéria seca na parte aérea dos tratamentos que receberam a bactéria em toletes não tratados termicamente no período experimental pode ser justificado, pelo menos em parte, pelo dreno de fotoassimilados promovidos pela competição com a flora natural dos toletes na colonização. Uma explicação adicional reside da competição entre a estirpe inoculada (HRC 54) e as bactérias que naturalmente colonizam o tolete, limitando o estabelecimento endofítico da mesma e, por via de conseqüência, as respostas positivas sobre o incremento de biomassa da planta hospedeira.

As bactérias estimularam o crescimento radicular dos toletes tratados termicamente, ocasionando incremento de massa ao redor de $120 \%$ em relação às plantas-controle, semelhantemente ao efeito observado com AH (Figura 1). O uso em conjunto de bactérias e AH promoveu aumento de $81 \%$ na matéria seca de raízes em relação ao controle, nos toletes tratados termicamente; contudo, este aumento não foi significativo para o teste de médias de Tukey (5\%). $\mathrm{Na}$ ausência de tratamento térmico, a aplicação de $\mathrm{AH}$ resultou em incremento significativo de massa radicular (Figura 1). O uso em conjunto de $\mathrm{AH}$ e $H$. seropedicae em microtoletes sem termoterapia também resultou em incremento de matéria seca de raízes porém em menor magnitude e não-significativo pelo teste de médias de Tukey (5\%). 


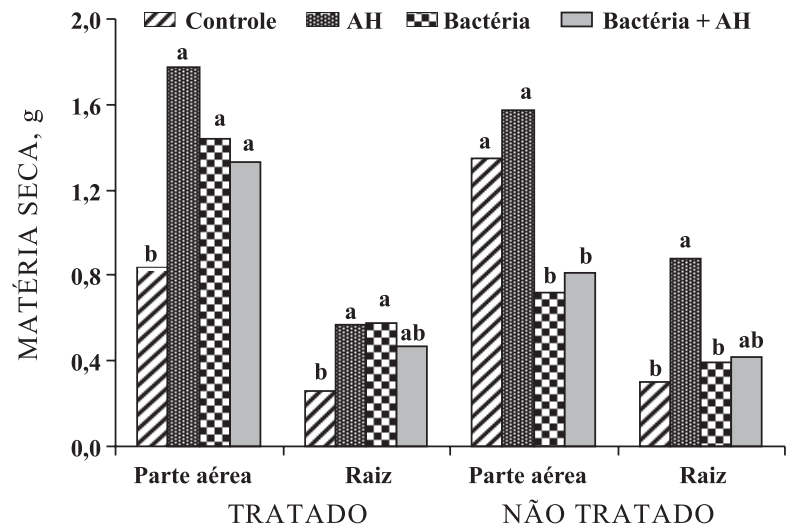

Figura 1. Matéria seca da parte aérea e de raízes de microtoletes de cana-de-açúcar cv RB 72-454 tratados termicamente com água a $50,5^{\circ} \mathrm{C}$ por duas horas (tratado) ou não (não tratado) e submetidos à imersão por $12 \mathrm{~h}$ numa solução que continha: água (controle), ácidos húmicos (AH) na concentração de $20 \mathrm{mg} \mathrm{L}^{-1}$ de $\mathrm{C}_{\mathrm{AH}}$, Herbaspirilum seropedicae estirpe HRC 54 na concentração de $10^{8} \mathrm{~mL}^{-1}$ de células em água (Bac) e pelo uso em conjunto de AH e bac (Bactéria + AH). Médias seguidas por letras diferentes são estatisticamente diferentes pelo teste Tukey $(p<0,05) . N=4 ; C V=26 \% ; F=5$.

Foi observado um estímulo médio na ordem de $60 \%$ no comprimento radicular das plântulas de cana-deaçúcar tratadas com bactérias e próximo a 118 \% pelos $\mathrm{AH}$, ambos com ou sem tratamento térmico (Figura 2a). O uso combinado de $\mathrm{AH}$ e bactérias também estimulou o comprimento radicular em relação ao controle (Figura 2a). Quando foi realizado o tratamento térmico, todos os tratamentos promoveram estímulo no comprimento radicular (Figura 2a). A área radicular foi significativamente aumentada pelos tratamentos em comparação com as plantas-controle nos microtoletes tratados termicamente, com destaque para o uso de bactérias e uso combinado BacAH. Esse resultado indica que a presença de $\mathrm{AH}$ em conjunto com bactérias não é prejudicial aos estímulos causados pelas bactérias isoladamente, e vice-versa. Como esperado, na ausência da termoterapia, os tratamentos com bactérias apresentaram menor estimulação, provavelmente em virtude da competição com a população de microrganismos naturalmente presente nos toletes (Sanhueza, 1979; Pimentel et al.,1991).

A população de bactérias diazotróficas introduzida aumentou significativamente nas raízes dos toletes que receberam inoculação de bactérias com a termoterapia. $\mathrm{O}$ uso em conjunto de $\mathrm{AH}$ não alterou significativamente o tamanho da população de bactérias (Figura 3). Com a utilização de bactérias em conjunto com $\mathrm{AH}$, nos toletes previamente tratados termicamente, a população da bactéria inoculada promoveu aumento de cerca de 100 vezes, demonstrando, assim, um potencial para persistência do inóculo e aumento de amplitude de resposta (Figura 3). Na ausência de tratamento, o nível populacional não foi alterado de maneira significativa, provavelmente por causa da competição por fotoassimilados e por nichos de colonização entre os microrganismos nos toletes, o que corrobora os dados de acúmulo de biomassa.

$\mathrm{Na}$ ausência do tratamento térmico, a promoção do crescimento vegetal deveu-se, principalmente, ao efeito proporcionado pelos $\mathrm{AH}$. A presença de bactérias diazotróficas naturalmente associadas ao material propagativo antes da inoculação de $H$. seropedicae HRC 54, cerca de $10^{4}$ células bacterianas (Figura 3), nos toletes não tratados termicamente, parece reduzir a capacidade de estabelecimento e potencial de promoção de crescimento do inóculo, graças, prova-
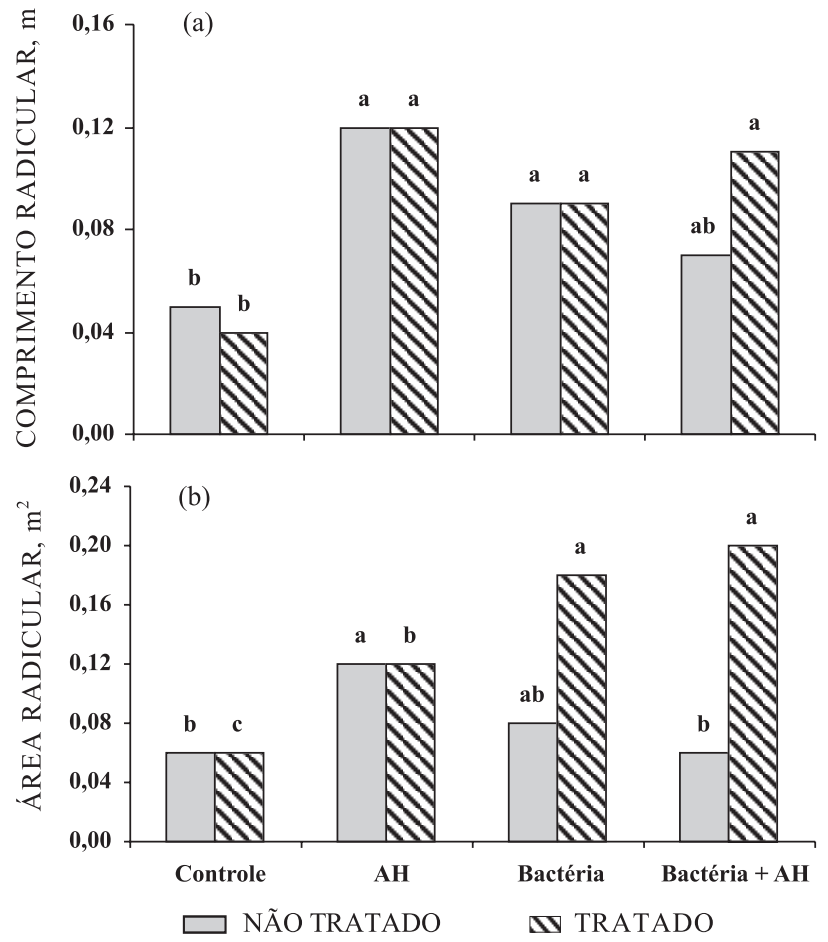

Figura 2. Comprimento radicular total (a) e área superficial radicular (b) estimados pelo software Delta T-scan (demo version) de microtoletes de cana-de-açúcar cv RB 72-454 tratados termicamente com água a $50,5^{\circ} \mathrm{C}$ por duas horas (tratado) ou não (não tratado) e submetidos à imersão por $12 \mathrm{~h}$ numa solução que continha: água (controle), ácidos húmicos (AH) na concentração de $20 \mathrm{mg} \mathrm{L}^{-1}$ de $\mathrm{C}_{\mathrm{AH}}$, Herbaspirilum seropedicae estirpe HRC 54 na concentração de $10^{8}$ células $\mathrm{mL}^{-1}$ de água (Bac) e pelo uso em conjunto de $\mathrm{AH}$ e bac (Bactéria + AH) Médias seguidas por letras diferentes são estatisticamente diferentes pelo teste Tukey $(\mathrm{p}<0,05)$. Comprimento: $\mathrm{N}=4$; $\mathrm{CV}=$ $23 \% ; \mathrm{F}=8$. Área: $\mathrm{N}=5 ; \mathrm{CV}=21 \% ; \mathrm{F}=3,2$. 


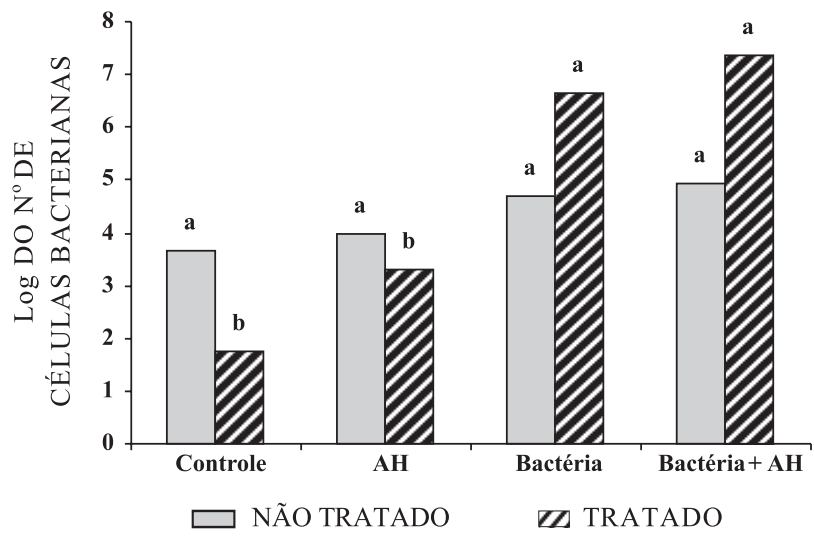

Figura 3. Nível populacional de Herbaspirilum seropedicae estirpe HRC 54 em raízes frescas de microtoletes (log do número de células bacterianas por grama de tecido fresco) de canade-açúcar cv RB 72-454 tratados termicamente com água a $50,5^{\circ} \mathrm{C}$ por duas horas (tratado) ou não (não tratado) e submetidos à imersão por 12 h numa solução que continha: água (controle), ácidos húmicos (AH) na concentração de $20 \mathrm{mg} \mathrm{L}^{-1}$ de $\mathrm{C}_{\mathrm{AH}}$, Herbaspirilum seropedicae estirpe HRC 54 na concentração de $10^{8} \mathrm{~mL}^{-1} \mathrm{de}$ células em água (Bac) e pelo uso em conjunto de AH e bac (Bactéria + AH). Médias seguidas por letras diferentes são estatisticamente diferentes pelo teste Tukey $(p<0,05)$.

velmente, à competição com outros microrganismos, seja por fotoassimilados da planta, sítios de colonização e espaço físico, seja por outras interações, como antibiose, a qual se traduz no fato de a biota natural sintetizar compostos com ação bacteristática e bactericida. Após o tratamento térmico, o decréscimo da biota nativa reduziu a competição, facilitando o estabelecimento da bactéria inoculada e, conseqüentemente, aumentando a probabilidade de respostas positivas à inoculação.

Observou-se a modificação significativa no crescimento e na arquitetura do tecido radicular dos microtoletes de cana-de-açúcar tratados termicamente pelo uso $\mathrm{AH}$, de $H$. seropedicae e pelo uso conjunto de substâncias húmicas e bactérias diazotróficas endofíticas. A maior área e comprimento radiculares correspondem à presença de maior número de raízes finas, fisiologicamente mais ativas e capazes de explorar melhor o substrato ou o solo. Os mecanismos responsáveis por esta estimulação no crescimento vegetal ainda não são bem esclarecidos. A presença de $\mathrm{N}$ nos $\mathrm{AH}$ e de outros nutrientes nas cinzas dos AH é muito baixa (produzindo uma concentração de $\mathrm{N}$ de $9,4 \times 10^{-7} \mathrm{~mol} \mathrm{~L}^{-1}, \mathrm{Si}=1,92 \times 10^{-5} \mathrm{~mol} \mathrm{~L}^{-1}, \mathrm{Fe}=$ $7,32 \times 10^{-6} \mathrm{~mol} \mathrm{~L}^{-1}, \mathrm{Al}=4,67 \times 10^{-7} \mathrm{~mol} \mathrm{~L}^{-1}, \mathrm{Zn}=$ $2,8 \times 10^{-8} \mathrm{~mol} \mathrm{~L}^{-1}$ e de $\mathrm{Cu}=7,7 \times 10^{-9} \mathrm{~mol} \mathrm{~L}^{-1}$ ), desta forma, efeitos nutricionais diretos ou associados ao aumento da solubilidade de complexos organominerais não poderiam justificar isoladamente a magnitude observada nos incrementos de crescimento radicular.
Façanha et al., (2002) e Canellas et al. (2002), relataram a possibilidades de efeitos estimulantes semelhantes aos dos hormônios vegetais, pois verificaram que $\mathrm{AH}$ isolados do mesmo vermicomposto são capazes de promover aumento na síntese de $\mathrm{H}^{+}$ATPases de membrana plasmática (MP) em mono e dicotiledôneas. Essa enzima apresenta papel central na capacidade de adaptação das plantas ao ambiente, uma vez que fornece energia por meio da formação de um gradiente eletroquímico originado da hidrólise de ATP necessário tanto para a ação dos transportadores unipórteres e simpórteres, como para o aumento da concentração de $\mathrm{H}^{+}$no apoplasto, gerando $\mathrm{pH}$ ácido suficiente para ação de hidrolases capazes de romper ligações e favorecer o afrouxamento da parede celular e, por conseqüência, expansão de células, tecidos e órgãos vegetais.

Essa seqüência de eventos bioquímicos, que resulta em maior número de células e crescimento de tecidos radiculares mais finos, é conhecida como teoria do crescimento ácido (Rayle \& Cleland, 1992; Cosgrove, 1997). A indução da síntese de ATPases de membrana plasmática (MP) é um fenômeno tipicamente mediado por sinais moleculares, tais como os promovidos pelas auxinas (Frias et al., 1996). Muscolo et al (1998) e Façanha et al. (2002) encontraram, por diferentes meios, a presença de moléculas semelhantes às auxinas em substâncias húmicas. Quaggiotti et al. (2004) comprovaram os trabalhos anteriores verificando a presença de AIA na estrutura de SH por meio de um ensaio imunológico. Foi demonstrado que frações húmicas de baixo peso molecular estimulam a absorção de nitrato, possivelmente pelo aumento da isoforma Mha2 da $\mathrm{H}^{+}$-ATPase de MP. Zandonadi (2006) comprovou a ação auxínica de AH isolados de vermicomposto pelo uso de plantas mutantes insensíveis a esse hormônio vegetal. A aplicação dos $\mathrm{AH}$ nos mutantes dgt de tomateiro não provocou alteração no sistema radicular, indicando que a via de sinalização das SH na promoção do crescimento radicular é a mesma via de sinalização celular usada pelas auxinas. Estes mecanismos explicam os estímulos significativos encontrados nos microtoletes sob tratamento com $\mathrm{AH}$, independente-mente da termoterapia (Figuras 1 e 2).

Por sua vez, os resultados significativos obtidos com a inoculação de bactérias, principalmente nos microtoletes que sofreram termoterapia (Figuras $1 \mathrm{e}$ 2 ), podem ser devidos a mecanismos semelhantes aos dos AH. Bastian et al. (1998) verificaram que $H$. seropedicae é capaz de produzir e liberar para o meio de crescimento quantidade significativa de ácido 3 indol acético. Nesse sentido, Radwan et al. (2004), inoculando arroz e trigo com diferentes espécies de Herbaspirilum, observaram marcante promoção do crescimento radicular e relacionaram essa promoção diretamente com a produção de auxinas. Alterações significativas na arquitetura radicular dos microtoletes inoculados com bactérias endofíticas tratados termicamente (Figuras 1 e 2) foram 
semelhantes aos resultados encontrados por Olivares et al. (2002), em mudas micropropagadas de cana-deaçúcar inoculadas com bactérias diazotróficas endofíticas. Esses autores constataram aumento na atividade das $\mathrm{H}^{+}$-ATPases isoladas de MP provenientes de raízes infectadas por bactérias diazotróficas endofíticas, típico do efeito induzido por auxinas, evidenciados pelo aumento do número de sítios de mitose, de raízes emergidas do eixo principal e, consequentemente, pelo aumento da área radicular.

Para toletes que não sofreram termoterapia, respostas consistentes foram obtidas apenas pela aplicação isolada de ácidos húmicos, com pouco ou nenhuma influência da bacterização com $H$. seropedicae estirpe HRC 54 sobre a biomassa e geometria das raízes. Já nos toletes tratados termicamente, o uso em conjunto de AH e bactérias diazotróficas endofíticas pode ser estratégia importante para aumento do "pegamento" desse material propagativo no campo, pelo efeito de promoção do crescimento radicular, reduzindo a mortalidade e incrementando o vigor de toletes (principalmente tratados termicamente), melhorando a eficiência de uso de nutrientes pelas alterações na arquitetura do sistema radicular, além de disseminar estirpes de bactérias diazotróficas endofíticas selecionadas para competir e realizar a fixação biológica de $\mathrm{N}_{2}(\mathrm{FBN})$. Pequenos incrementos derivados da FBN, numa cultura estratégica como a cana-de-açúcar, podem representar para o Brasil ganhos difíceis de ser contabilizados que vão desde a economia de recursos gastos com fertilizantes provenientes de fontes nãorenováveis até o incremento de sustentabilidade para a produção agrícola. Trabalhos adicionais para avaliar o efeito do uso combinado de substâncias húmicas e bactérias diazotróficas endofíticas deverão ser alvo de novas pesquisas.

\section{CONCLUSÕES}

1. As características de biomassa e crescimento radicular foram mais estimuladas em toletes tratados termicamente.

2. Os AH promoveram o crescimento de parte aérea e raiz nos toletes de cana-de-açúcar, independentemente da termoterapia.

3. Nos toletes não tratados termicamente, a área radicular foi estimulada somente pelos $\mathrm{AH}$.

4. O tratamento térmico foi determinante na expressão dos efeitos positivos dos tratamentos com bactérias diazotróficas, bem como no aumento do tamanho da população das bactérias associadas às raízes

5. O uso em conjunto de $\mathrm{AH}$ e $H$. seropedicae estirpe HRC 54 não alterou o nível populacional das bactérias no tecido radicular.
6. Nos toletes tratados termicamente, o uso em conjunto de $\mathrm{AH}$ e $H$. seropedicae estirpe HRC 54 promoveu estímulo na biomassa da parte aérea, no comprimento e na área radicular

7. O uso em conjunto de $\mathrm{AH}$ e $H$. seropedicae estirpe HRC 54 foi superior ao efeito do AH isolado somente em relação à área radicular dos toletes tratados termicamente.

\section{AGRADECIMENTOS}

Este trabalho foi parcialmente financiado pelo CNPq (471910/2003-1), PRONEX, FAPERJ-“primeiros projetos" (E26/170.526/2004), IFS (c3391-1).

\section{LITERATURA CITADA}

BALDANI, V.L.D.; BALDANI, J.I.; OLIVARES, F.L. \& DÖBEREINER, J. Identification and ecology of Herbaspirillum seropedicae and the related Pseudomonas rubrisubalbicans. Symbiosis, 13:65-73, 1992.

BASTIÁN, F.; COHEN, A.; PICCOLI, P.; LUNA, V.; BARALDI, R. \& BOTTINI, R. Production of 3-idol-3-acetic acid and gibberellins A1 and A3 by Acetobacter diazotrophicus and Herbaspirillum seropedicae in chemically-defined culture media. Plant Growth Regul., 24:7-11, 1998.

CANELLAS, L.P. \& FAÇANHA, A.R. Chemical nature of soil humified fractions and their bioactivity. Pesq. Agropec. Bras., 39:233-240, 2004.

CANELLAS, L.P.; OLIVARES, F.L.; OKOROKOVAFAÇANHA, A.L. \& FAÇANHA A.R. Humic acids isolated from earthworm compost enhance root elongation, lateral root emergence, and plasma membrane $\mathrm{H}^{+}$-ATPase activity in maize roots. Plant Physiol., 130:1951-1957, 2002.

CANUTO, E.L.; OLIVEIRA, A.M.L.; REIS, V.M. \& BALDANI, J.I. Avaliação da contribuição da fixação biológica de nitrogênio em cana-de-açúcar originada de sementes e inoculada com endófitos fixadores de nitrogênio. Braz. J. Microbiol., 34:62-64,2003.

CARNEIRO JR; J.B.; SILVEIRA, S.F.S.; SOUZA FILHO, G.A.; OLIVARES, F.L. \& GIGLIOTI, E.A. Especificidade de anti-soro policlonal à Leifsonia xyli subsp. Xyli. Fitopatol. Bras., 29: 614-619, 2004

CHAGAS, P.R.R. \& MATSUOKA, S. Medidas de controle do raquitismo da soqueira. Brasil Açuc., 106:40-44, 1988.

CHEN, Y. \& AVIAD, T. Effects of humic substances on plant growth. In: MAcCARTHY, P.; CLAPP, C.E.; MALCOM, R.L. \& BLOOM, P.R., eds. Humic substances in soils and crop science: Selected readings. Madison, Soil Science Society of America, 1990. p.161-186.

CHEN, Y.; CLAPP, C.E. \& MAGEN, H. Mechanisms of plant growth stimulation by humic substances: The role of organo-iron complexes. Soil Sci. Plant Nutr., 50:1089-1095, 2004.

COSGROVE, D.J. Relaxation in a high-stress environment: The molecular bases of extensible cell walls and cell enlargement. Plant Cell, 9:1031-1041, 1997. 
DÖBEREINER, J. History and new perspectives of diazotrophs in association with non-leguminous plants. Symbiosis, $13: 1-13,1992 b$

DÖBEREINER, J. Recent changes in concepts of plant bacteria interactions: Endophytic $\mathrm{N}_{2}$ fixing bacteria. Ci. Cult., 44:310-313, 1992a.

DÖBEREINER, J.; BALDANI, V.L.D. \& BALDANI, J.I. Como isolar e identificar bactérias diazotróficas de plantas nãoleguminosas. Brasília, Embrapa-SPI: Itaguaí,. EmbrapaCNPAB, 1995. 60p.

EMPRESA BRASILEIRA DE PESQUISA AGROPECUÁRIA EMBRAPA. Centro Nacional de Pesquisa de Solos. Sistema brasileiro de classificação de solos. Brasília, Embrapa Produção de Informação, 1999. 412p.

FAÇANHA, A.R.; FAÇANHA, A.L.O.; OLIVARES, F.L.; GURIDI, F.; SANTOS, G.A.;VELLOSO, A.C.X.; RUMJANEK, V.M.; BRASIL, F.; SCHRIPSEMA, J.; BRAZ-FILHO, R.; OLIVEIRA, M.A. \& CANELLAS, L.P. Bioatividade de ácidos húmicos: Efeito sobre o desenvolvimento radicular e sobre a bomba de prótons da membrana plasmática. Pesq. Agropec. Bras., 37:13011310, 2002

FRIAS, I.; CALDEIRA, M.T.; PEREZ, C.J.R.; NAVARRO, A.J.P.; CULIANEZ, M.F.A.; KUPPINGER, O.; STRANSKY, H.; PAGES, M.; HAGER, A. \& SERRANO, R. A major isoform of the maize plasma membrane $\mathrm{H}^{+}$-ATPase: Characterization and induction by auxin in coleoptiles. Plant Cell, 8:1533-1544, 1996.

KIMATI, I.; AMORIM, L.; REZENDE, J.A.M.; BERGAMIN FILHO, A. \& CAMARGO, L.E.A. Manual de fitopatologia. 4.ed. São Paulo, Agronômica Ceres, 2005. v.2. 651p.

MUSCOLO, A.; CUTRUPI, S. \& NARDI, S. IAA detection in humic substances. Soil Biol. Biochem., 30:1199-1201, 1998.

NARDI, S.; PIZZEGHELLO, D.; MUSCOLO, A. \& VIANELLO, A. Physiological effects of humic substances on higher plants. Soil Biol. Biochem., 34:1527-1536, 2002.

OLIVARES, F.L.; FERREIRA, F.P.; SILVA, L.G.; FAÇANHA, A.R.; RAMOS, A.C., NETTO, A.T.; CAMPOSTRINI, E.; REIS, V.M. \& MIGUENS, F.C. Physiological changes induced on the host plant during the endophytic interaction between sugar cane and diazotrophic bacteria. In: INTERNATIONAL SYMPOSIUM ON NITROGEN FIXATION WITH NON-LEGUMES, 9., Leuven, 2002. Book of Abstrats, Leuven, 2002. p.38-38.

OLIVARES, F.L.; REIS, V.M. \& FACAANHA, A.R. The role of endophytic diazotrops in sugarcane rootmorphogenesis and development. In: FINAN, T.M.; O'BRIAN, M.R.; LAYZELL, D.B., VESSEY, J.K. \& NEWTON. W., eds. Nitrogen fixation: Global perspectives. Oxon, CAB International, 2000. p.476-477.

OLIVARES, F.L.; REIS, V.M.; FACANHA, A.R.; BALDANI, J.I.; BALDANI, V.L.; FERREIRA, F.P.; BATISTA, Q.R.; BARRETO, B.R.; SILVA, L.G.; AZEVEDO, I.G.; BRASIL, F.C.; ROSSIELO, R.O.P.; MIGUENS, F.C. \& JAMES, E.K The role of endophytic diazotrophs in sugarcane root morphogenesis and development. In: INTERNATIONAL $\mathrm{N}_{2}$ FIXATION CONGRESS, NITROGEN FIXATIONGLOBAL PERSPECTIVES, 13., Hamilton, 2001. Proceedings. Oxford, CABI Publishing, 2001. p.471-471.
OLIVEIRA, A.L.M.; URQUIAGA, S.; DÖBEREINER, J. \& BALDANI, J.I. The effect of inoculating endophytic $\mathrm{N}_{2}$ fixing bacteria on micro propagated sugarcane plants. Plant Soil, 242:205-215, 2002

PIMENTEL, J.P.; OLIVARES, F.; PITARD, R.M.; URQUIAGA, S.; AKIBA, F. \& DOBEREINER, J. Dinitrogen fixation and infection of grass leaves by Pseudomonas rubrisubalbicans and Herbaspirillum seropedicae. Plant Soil, 137:1:61-65, 1991.

PINTON, R.; CESCO, S.; IACOLETTI, G.; ASTOLFI, S. \& VARANINI, Z. Modulation of nitrate uptake by waterextractable humic substances: Involvement of root plasma membrane $\mathrm{H}^{+}$-ATPase. Plant Soil, 215:155-163, 1999

QUAGGIOTTI, S.; RUPERT, B.; PIZZEGHELLO, D.; FRANCIOSO, O.; TUGNOLI, V. \& NARDI, S. Effect of low molecular size humic substances on nitrate uptake and expression of genes involved in nitrate transport in maize (Zea mays L.). J. Exp. Bot., 55:803-813, 2004.

RADWAN, T.EL-S.; MOHAMED, Z.K. \& REIS, V.M. Efeito da inoculação de Azospirillum e Herbaspirillum na produção de compostos indólicos em plântulas de milho e arroz. Pesq. Agropec. Bras., 39:987-994, 2004.

RAYLE, D.L. \& CLELAND, R.E. The acid growth theory of auxin-induced cell elongation is alive and well. Plant Physiol., 9:271-1274, 1992.

REIS, V.M.; OLIVARES, F.L. \& DÖBEREINER, J. Improved methodology for isolation of Acetobacter diazotrophicus and confirmation of its endophytic habitat. World J. Microbiol. Biotechnol., 10:401-405, 1994.

RODRIGUES NETO, J.; MALAVOLTA, J. \& VICTOT, O. Meio simples para isolamento e cultivo de Xanthomonas campestris pv. citri Tipo B. Suma Phytopathol.,12:16, 1986.

SANHUEZA, R.M.V. Relações entre Xanthomonas albilineans, Erwinia herbicola e Pseudomonas sp. em cana-de-açúcar. Piracicaba, Escola Superior de Agricultura Luiz de Qureiroz, 1979. 77p. (Tese de Mestrado)

URQUIAGA, S.; CRUZ, H.S. \& BODDEY, R.M. Contribution of nitrogen fixation to sugarcane: Nitrogen-15 and nitrogen balance estimates. Soil Sci. Soc. Am. J., 56:105114,1992

VARANINI, Z.; PINTON, R.; DE BIASI, M.G.; ASTOLFI, S. \& MAGGIONI, A. Low molecular weight humic substances stimulated $\mathrm{H}^{+}$-ATPase activity of plasma membrane vesicles isolated from oat (Avena sativa L.) roots. Plant Soil, 153:61-69, 1993.

VAUGHAN, D. \& MALCOM, R.E. Influence of humic substances on growth and physiological processes. In: AUGHAN, D. \& MALCOM, R.E., eds. Soil organic matter and biological activity. Dordrecht, Martinus Nijhoff/ Junk W, 1985. p. 37-76.

ZANDONADI, D.B. Bioatividade de ácidos húmicos: Promoção do desenvolvimento radicular e atividade das bombas de $\mathrm{H}^{+}$. Campos dos Goytacazes, Universidade Estadual do Norte Fluminense, 2006. 161p. (Tese de Mestrado) 